\title{
Evaluation of Lignin-Calcium Complex as Thermal Stabilizer for Poly Vinyl Chloride
}

\author{
Hussein Ali Shnawa \\ Polymer Research Center, University of Basrah, Basrah, Iraq. \\ Email: hussanqi@yahoo.com \\ Received December 27 ${ }^{\text {th }}$, 2010; revised March $18^{\text {th }}, 2011$; accepted May $19^{\text {th }}, 2011$.
}

\begin{abstract}
Chemical modification of lignin was carried out by reacted it with $\mathrm{HI}$ acid, then the modified lignin treated with calcium hydroxide to prepare calcium-lignin chelating complex, this derivative was examined as thermal stabilizer for $P V C$, thermal degradation of PVC neat as blank and containing three weight percents $(1,2$, and 4$)$ into polymer was accelerated by heat treatment at $190^{\circ} \mathrm{C}$ for $2 \mathrm{~h}$ then PVC films were casting from THF solvent with thickness $0.03 \mathrm{~mm}$. Thermal stabilization activity of this derivative was investigated by using infrared spectroscopy, according to the results obtained Calcium-lignin complex have suitable activity to increased PVC stability at low concentration depending on it's ability to reaction with $\mathrm{HCl}$ as well as the chemical structure of lignin that contain phenolic properties.
\end{abstract}

Keywords: Lignin, Modification of Lignin, Poly (Vinyl Chloride), Thermal Degradation, IR Study

\section{Introduction}

Lignin has a highly branched chemical structure consisting of phenol propane unites which are connected mainly together by ether or $\mathrm{C}-\mathrm{C}$ linkages [1,2]. Because of variety functional groups in lignin that provide many potential reactive sites for chemical modifications and applications, one of these modification method that used to increase lignin activity were by reacted it with formaldehyde in alkaline solution to form methylol groups into lignin matrix $[3,4]$, or by synthesized polymer from lignin on the basic of some functional groups such as phenylene, hydroxyl and methoxyl [5].

There are other studies show that the modification lignin by oxidation reaction (obtained through several sources and methods) can be used as chelating agent for some type of metal ions [6,7]. German C. Quintana and his co-worker study the capacity for removal of heavy metals from liquid streams by formation of complexes with lignin's oxidized by acid treatment and their conclusions refer to lignin capable of adsorbing Cadmium ions from aqueous solution and a slight increase in adsorption capacity when lignin was oxidized [8]. Another study show the used of native lignin as will as modification lignin as additive for low density polyethylene which can act as antioxidant and UV-stabilizers [9].

On the other hand, Poly (vinyl chloride), PVC, is one of the leading thermoplastic materials. It stands second in the world after polyethylene so far as production is concerned. However, PVC shows low thermal stability [10]. It is generally accepted that poly(vinyl chloride), PVC, is an unstable polymer when exposed to high temperatures during it's moldings and applications. Therefore, the poor thermal stability of PVC still remains one of its main problems [11]. The purpose of this work was to study the chemical modification of lignin by chelated it with Ca ion then evaluated its effect on thermal stability of poly (vinyl chloride).

\section{Experimental}

\subsection{Modification of Lignin}

15 g Lignin (Kraft lignin) from paper industries-Basrah was modified by refluxed it with $60 \mathrm{ml}$ of $30 \%$ solution of HI acid (May \& Baker Ltd.) for $3 \mathrm{~h}$ at the end or the reaction period the solution was allowed to cool before filtrated. Modified lignin washed with distillation water several times and finally dried under reduced pressure for 24 h.

\subsection{Preparation of Calcium-Lignin Chelating Complex}

Modified lignin $10 \mathrm{~g}$ was dissolved in $250 \mathrm{ml}$ water and added periodically $10 \%$ of $\mathrm{Ca}(\mathrm{OH})_{2}$ as clear and fil- 
trated solution with hand stirring. the addition was contious to precipitate all lignin in the mixture as brown dark powder which was filtered and washed to removal the non reacted $\mathrm{Ca}(\mathrm{OH})_{2}$, finally the product was oven drying for $24 \mathrm{~h}$ at $50^{\circ} \mathrm{C}$.

\subsection{Preparation of PVC Samples}

Commercial polyvinyl chloride (supplied from petrochemical industries Basrah) with K-value 66, volume density $0.45 \mathrm{gm} / \mathrm{cm}^{2}$ and without thermal stabilizer was mixed thermally by hakee thermal mixer (hakee rheocord torque rheometer) at $170^{\circ} \mathrm{C}$ with $60 \mathrm{rpm}$ with Ca-lignin chelating complex at three weight percentage $(1,2$, and 4)\% w/w and $0 \%$ as blank, the samples were compression molded at $170^{\circ} \mathrm{C}$ under $5 \mathrm{MPa}$ for $5 \mathrm{~min}$. to get sheets .

\subsection{Thermal Degradation Condition}

Accelerated PVC degradation was performed by fixed the samples in the oven at $190^{\circ} \mathrm{C}$ for $2 \mathrm{~h}$ under air as atmosphere.

\subsection{Films Preparation}

PVC samples were dissolved in THF then filtrated to remove Ca-lignin chelating or other compounds from PVC polymer. PVC was re-precipitated from THF solution by ethanol and filtrated, fixed concentration from PVC (0.1/5 ml)in THF were casting on class plate to prepare polymer film with $0.03 \mathrm{~mm}$ thickness (measured by Starrett micrometer, Jedburgn Scotland), the films were further dried at $40^{\circ} \mathrm{C}$ for $24 \mathrm{~h}$.

\subsection{Infrared Analysis}

IR-spectrophotometer that used in our study was Shimatzu-FTIR-8400S infrared sepectrometer for measurement infrared sepecrometry of lignin, modified lignin, and Ca-lignin chelating complex after dried, ground and mixed with $\mathrm{KBr}$ and pressed to form pellets. The infrared spectrometry of PVC samples as films specimens were placed in the path of IR beam, all spectrums were recorded in the range $4000-600 \mathrm{~cm}^{-1}$.

\section{Results and Discussion}

One modification method have been made on the Deetherfication of methoxyl groups of the guaiacyl propane and syringyl propane units by reacted lignin with HI acid this reaction lead to lignin molecule containing more phenolic hydroxyl groups [9].

FTIR spectrum of lignin (Figure 1) and modified lignin (Figure 2) show the same basic absorption peaks of main chemical groups that contained in lignin.

One of these peaks the broad and strong peak at 3300 $3400 \mathrm{~cm}^{-1}$ that attributed to hydroxyl groups and the peaks at $1600 \mathrm{~cm}^{-1}$ and $1520 \mathrm{~cm}^{-1}$ corresponding to the absorption of double bonds of alkene and aromatic skeletal vibration. But the main differences in the chemical structure between lignin and modified lignin can be represented by that peak of phenolic hydroxyl at $1220 \mathrm{~cm}^{-1}$ which become more intense and the peak at $1120 \mathrm{~cm}^{-1}$ that attributed to the alcoholic hydroxyl and aliphatic ether which appear less intensity.

The chemical reaction of lignin with HI lead to clear

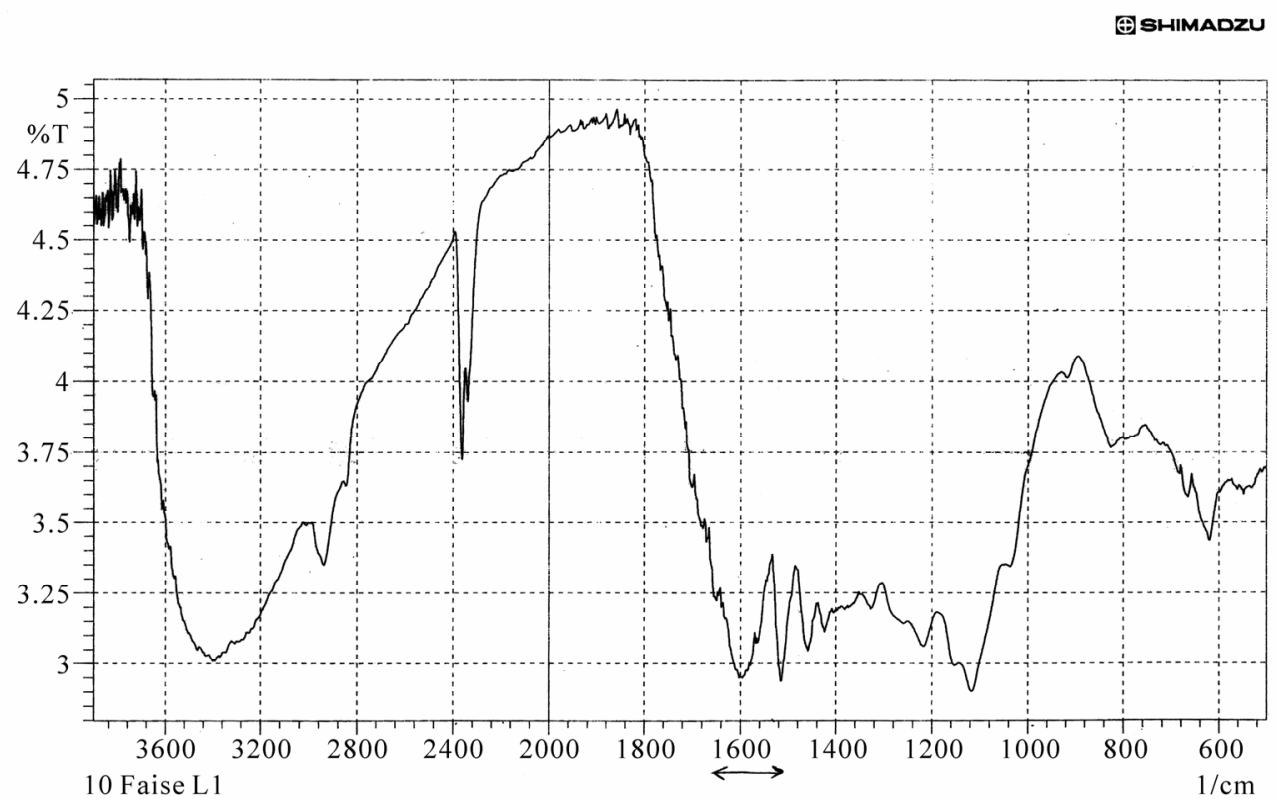

Figure 1. FTIR spectrum of unmodified lignin. 
increment in the intensity of these peaks due to increased the phenolic hydroxyl into modified lignin [9]. It's expected that the modification of lignin by above reaction lead to increased reactivity to some metal ions to form complex salts or chelating complexes; Figure 3 gives evidence of the chemical bonding occurring as consequence of the reaction modified lignin with $\mathrm{Ca}(\mathrm{OH})_{2}$ to formation chelating complex .

The major defferences between the two FTIR spectrum obtained from modified lignin and Ca-lignin chelate showed in Figure 2 and Figure 3, the presence of clear and broad peak at $1400 \mathrm{~cm}^{-1}$ and the sharp peak at 860 $\mathrm{cm}^{-1}$ that attributed to formed ionic bond (Ca-O) into this derivative [12]; One the other hand the absence the peak at $1220 \mathrm{~cm}^{-1}$ due to chelating phenolic groups with $\mathrm{Ca}^{2+}$ ion that refer to formation chelating salt.

Generally, infrared spectroscopy has been proven to be a highly effective means to qualitatively and quantitatively studies in polymer field where are deferent bonds and functional groups present in polymer which have

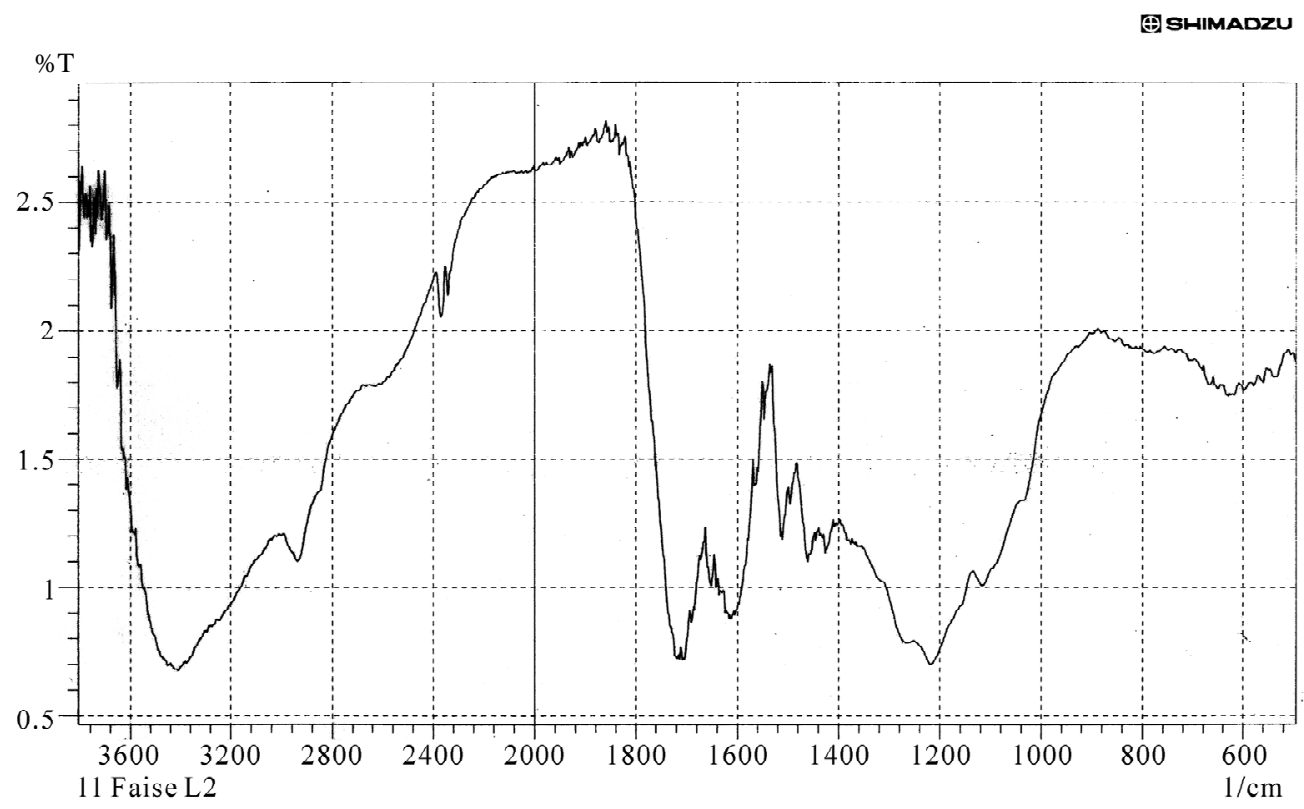

Figure 2. FTIR spectrum of modified lignin.

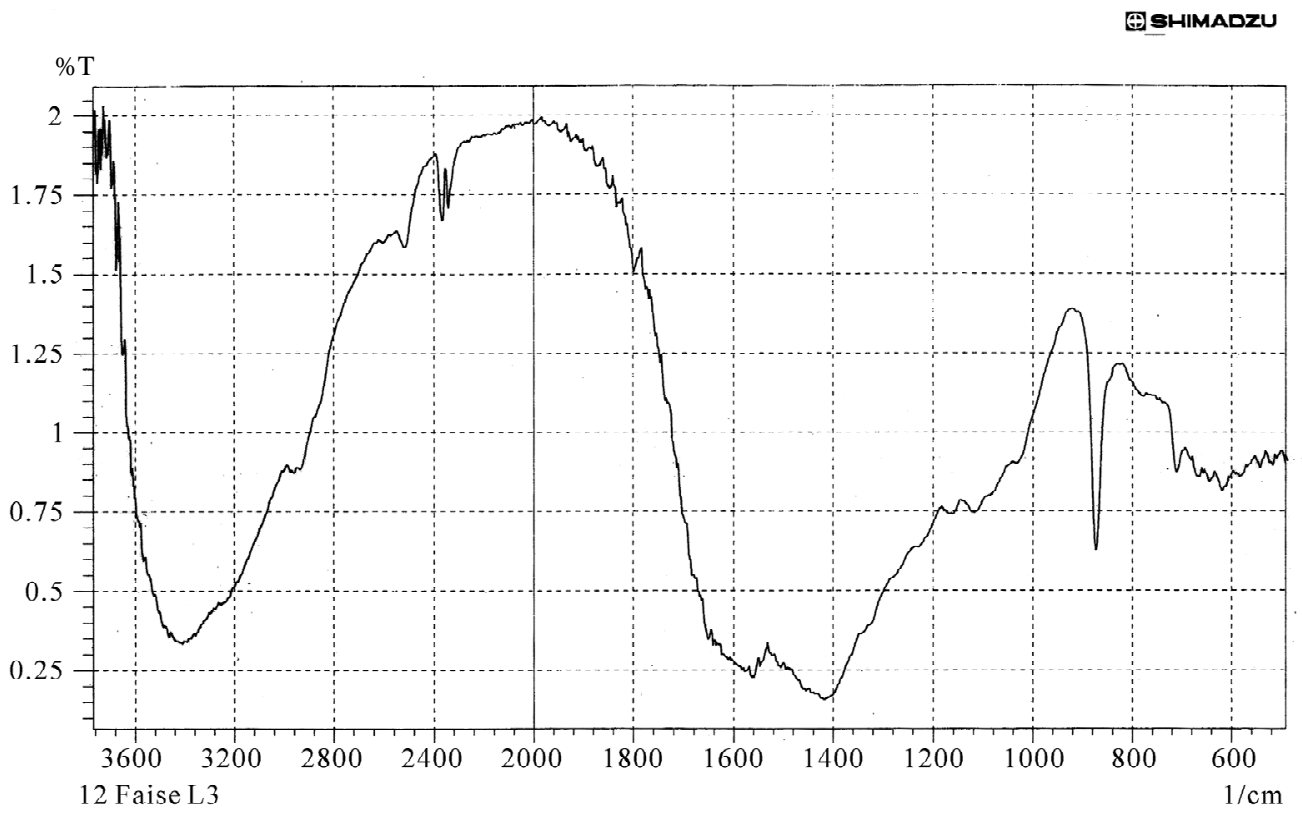

Figure 3. FTIR spectrum of Ca-lignin chelating complex. 
different vibration frequencies, and by identifying characteristic frequencies as absorption peaks can be detected and monitoring many functional groups in polymer structure and composites [13,14]. The application of infrared spectroscopy in polymer are concerned with the range 650 - $4000 \mathrm{~cm}^{-1}$; many works used IR or FTIR to study the decomposition and thermal degradation of PVC as well as evolution the thermal, photo-stabilizer and antioxidants additives for this polymer [11, 15-19].

Matuana L. M. (2001) classified the characteristic IR bands of PVC into three regions the first is called the $(\mathrm{C}-\mathrm{Cl})$ stretching region in the range from $600-700$ $\mathrm{cm}^{-1}$, the second region is attributed to $(\mathrm{C}-\mathrm{C})$ stretching in the region from $900-1200 \mathrm{~cm}^{-1}$ and the third region is at $1250-2970 \mathrm{~cm}^{-1}$ assigned to numerous $\mathrm{C}-\mathrm{H}$ mode. The IR spectrum of stander PVC without added thermal stabilizer or heat treatment is presented in Figure 4; absorption bands of this polymer evidenced at about 2950 cm which attributed to $\mathrm{C}-\mathrm{H}$ stretching from $\mathrm{CH}_{2}, 1440$ $\mathrm{cm}^{-1}$ wagging of $\mathrm{CH}_{2}, 1300 \mathrm{~cm}^{-1}$ of $\mathrm{CH}_{2}$ deformation, $1250 \mathrm{~cm}^{-1} \mathrm{C}-\mathrm{H}$ stretching from $\mathrm{CHCl}, 1070 \mathrm{~cm}^{-1} \mathrm{C}-\mathrm{C}$, $930 \mathrm{~cm}^{-1}$ rocking of $\mathrm{CH}_{2}, 700 \mathrm{~cm}^{-1}$ and $600 \mathrm{~cm}^{-1}$ stretching of $\mathrm{C}-\mathrm{Cl}$.

After degradation of PVC by heated it for $2 \mathrm{~h}$. at $190^{\circ} \mathrm{C}$ main differences occur in the chemical structure lead to found new chemical groups such as polyene, hydroxyl, carbonyl, cyclic compound and other [20,21], this new chemical structure can be observed and monitored by IR spectrometry; Figure 5 shows the IR spectra of PVC after decomposed with out any thermal stabilizer.

This spectrum contain clear and new deference peaks at several position where are not found in IR spectrum of stander PVC; (Figure 4) one of these peaks that appear at $3650 \mathrm{~cm}^{-1}$ which attributed to the free hydroxyl groups stretching vibration which can formed as a result to thermal-oxidation process, while in the state of PVC contain deferent percent from Ca-lignin chelating complex; Figure 6, Figure 7, and Figure 8, where in this samples the peak became much less intense or not found.

Additionally, clear peak can be detected in Figure 5, in the region between $3200-3400 \mathrm{~cm}^{-1}$ corresponding to absorption of hydroxyl with hydrogen bond, but this not found in the presence on lignin derivative at all \%wt. that mean increased PVC stability to thermal degradation by this additive where appear that the Ca-lignin chelating complex can be play a main role in the PVC stabilizing mechanism by it's chemical structure which can absorbed $\mathrm{HCl}$.

The intensified new strong and sharp at $1730 \mathrm{~cm}^{-1}$ in Figure 5 attributed to formation carbonyl groups as aliphatic ketone in PVC after heat treatment and this not found in PVC contain 1\% Figure 6 and became less intense in 2 wt\% sample, Figure 7; other significant peak used to study the thermal degradation of PVC, polyene

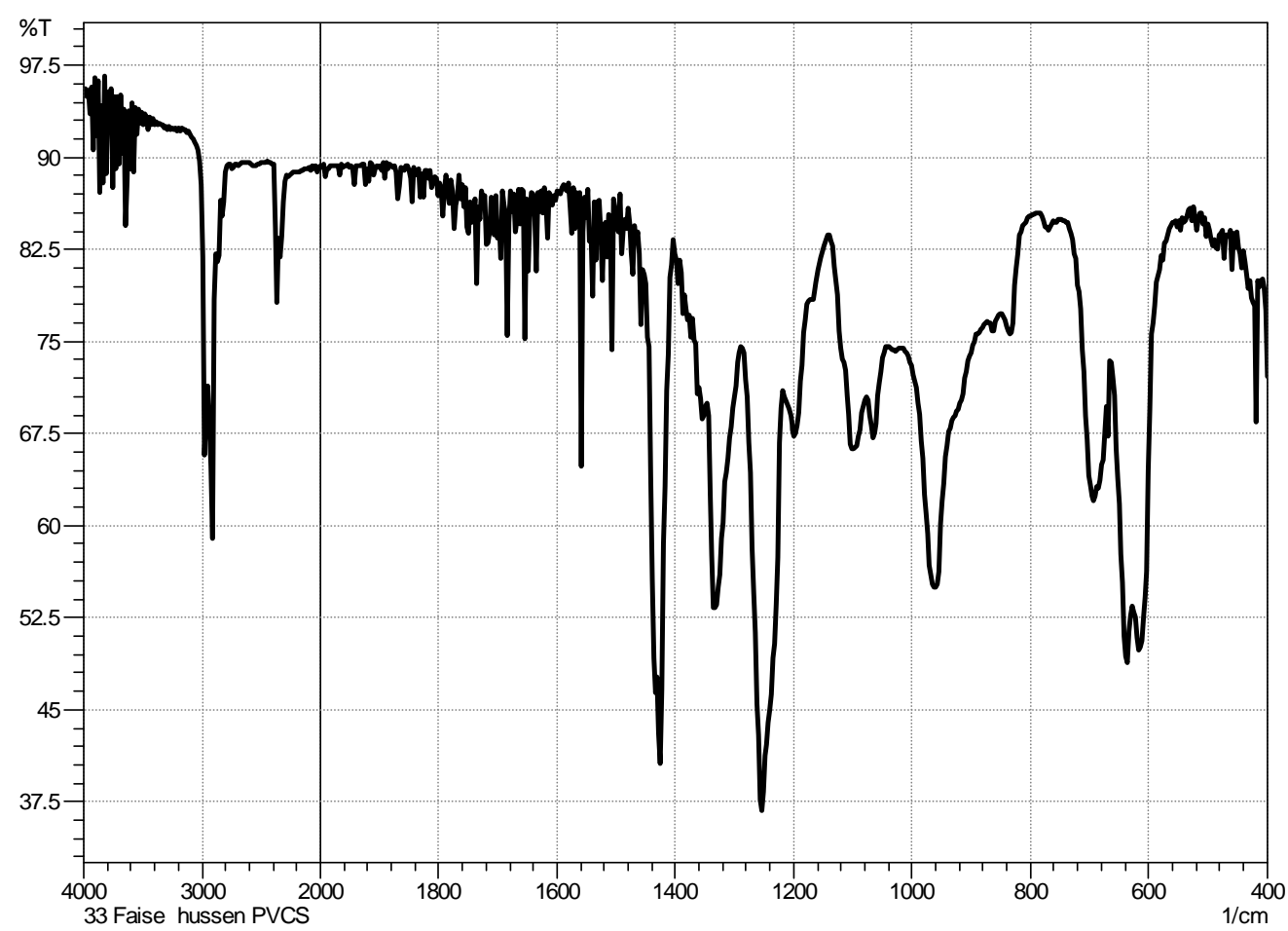

Figure 4. IR spectrum of pure PVC (blank). 


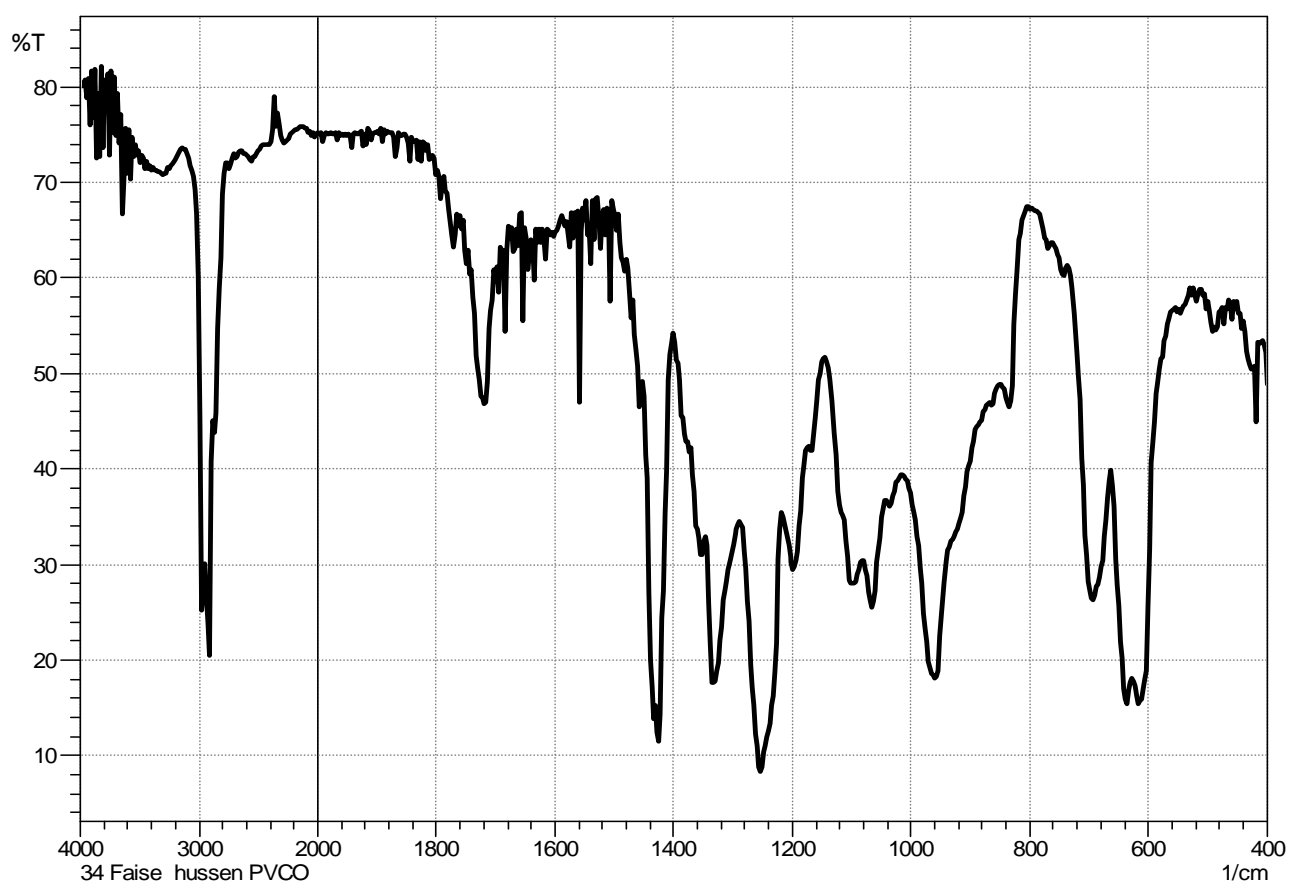

Figure 5. IR spectrum of pure PVC after degradation.

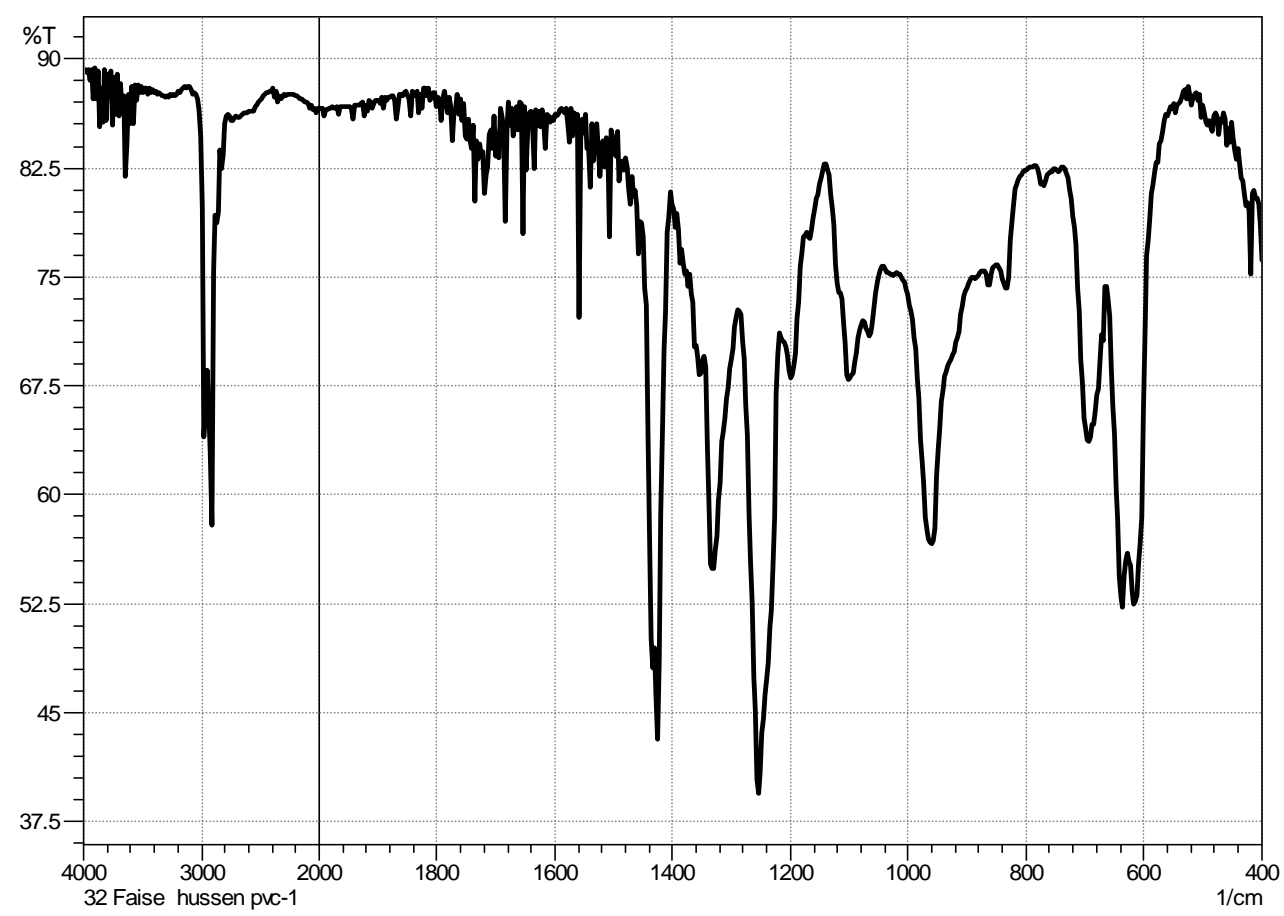

Figure 6. IR spectrum of PVC contain 1\% Ca-lig.chelating complex.

that formed in the first state of degradation process (Owen 1984) at 1602 - $1640 \mathrm{~cm}^{-1}$ which appear in Figures 5, 7 and $\mathbf{8}$ and not found in Figure 6, that mean the best activity can be achieved at less concentration from this derivative.
The absorption of the polyene and hydroxyl groups are used to follow the extend of polymer degradation by calculation polyene index $\left(I_{P e}\right)$ and hydroxyl index $\left(I_{O H}\right)$ and carbonyl index $\left(I_{C O}\right)$; as seen from Figure 9, Figure $\mathbf{1 0}$ and Figure 11 the presence of lignin derivative lead 


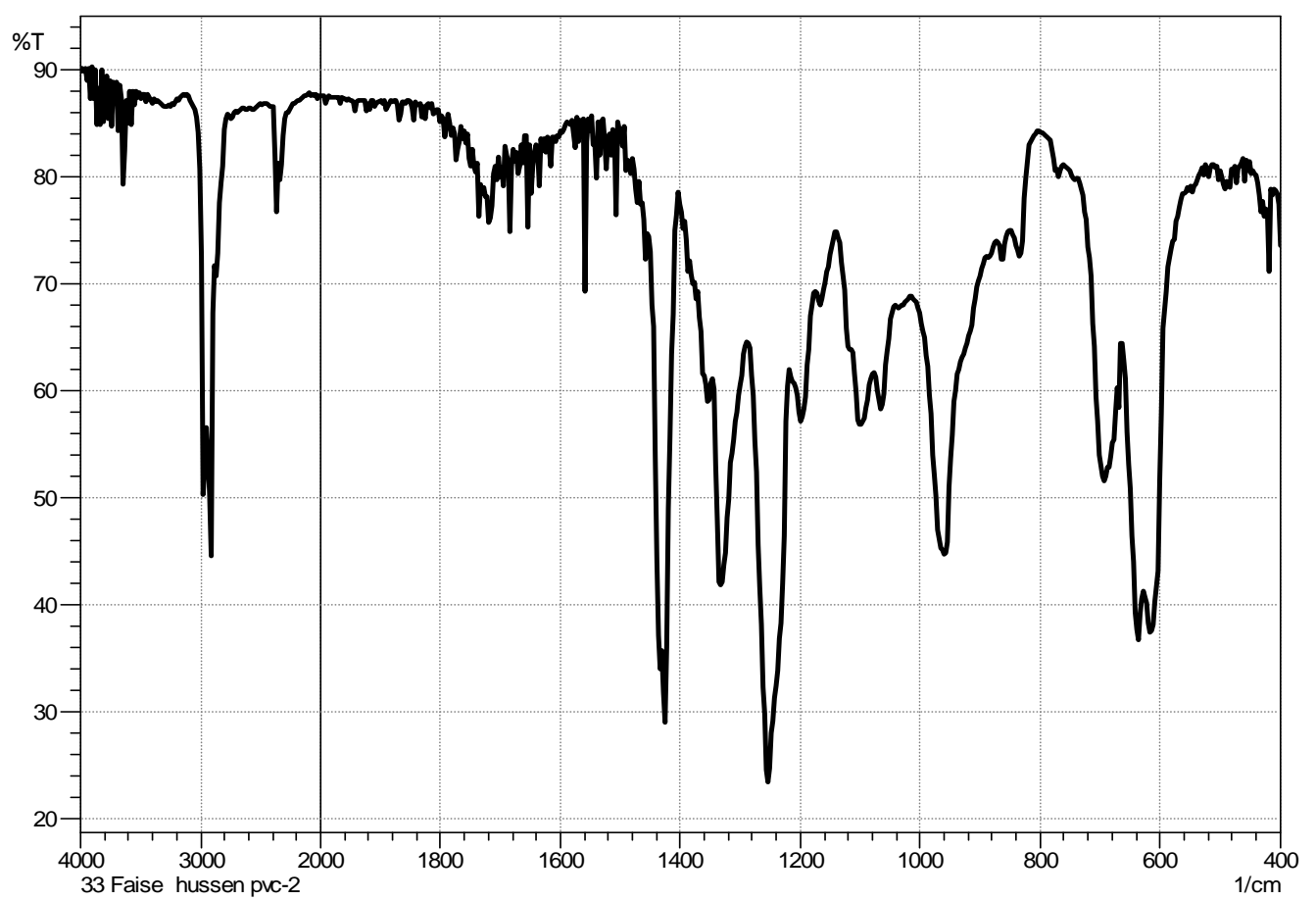

Figure 7. IR spectrum of PVC contain 2\% Ca-lig. chelating complex.

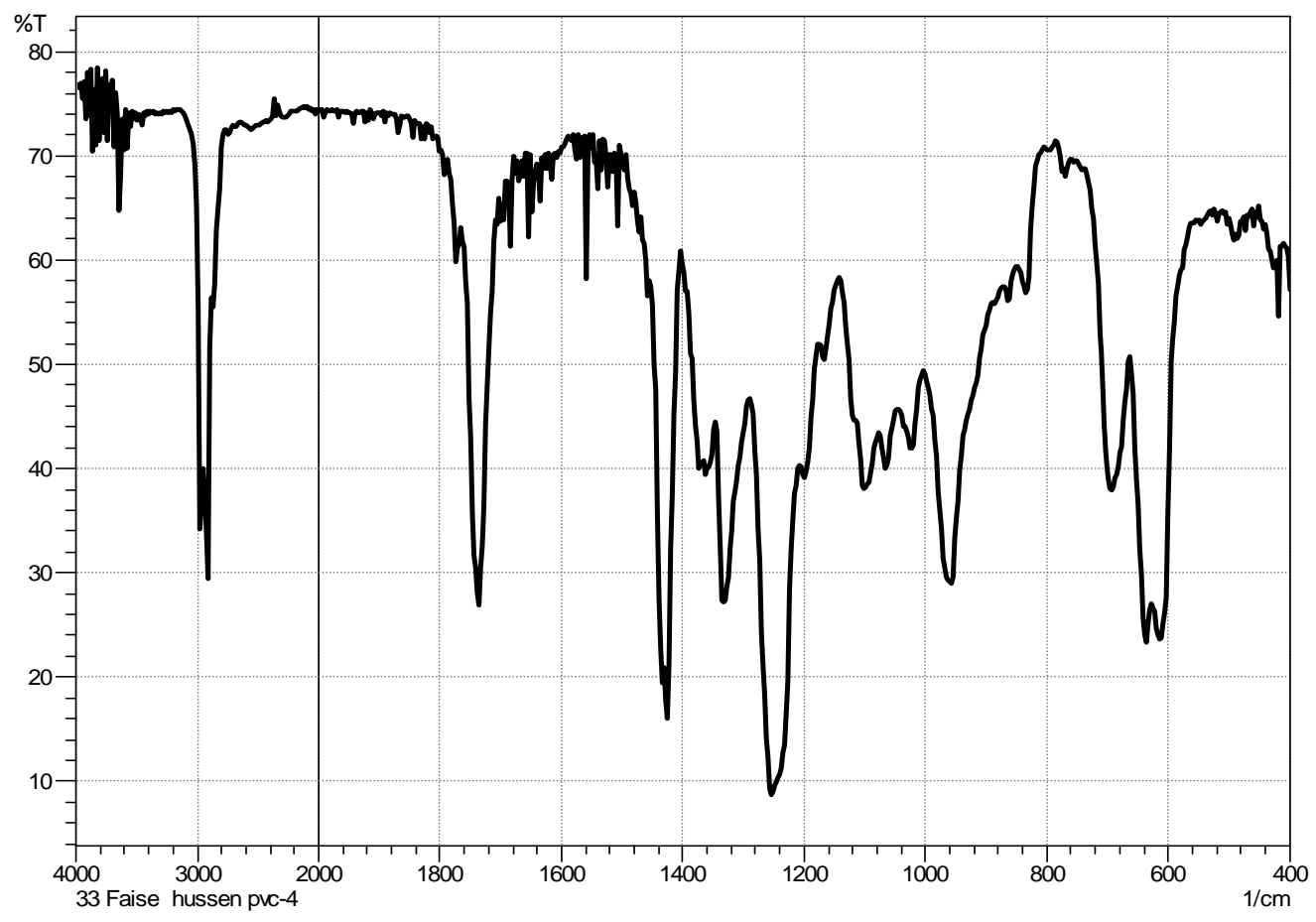

Figure 8. IR spectrum of PVC contain 4\% Ca-lig. chelating complex.

to lower growth rate of polyene and hydroxyl indices respectively, with increased the $\mathrm{wt} \%$ of this additive into PVC samples. Therefore, at $0 \%$ from lignin derivative the indices appear at higher values and decreased with increased $\mathrm{wt} \%$ into polymer.

\section{Conclusions}

1) The chemical reaction of lignin with HI acid lead to in- 


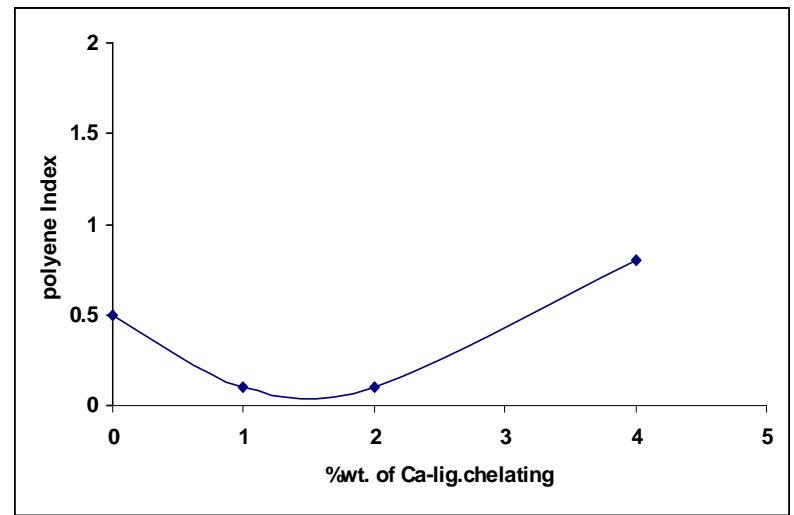

Figure 9. Relationship between the polyene indix and wt\% of Ca-lignin chelating complex.

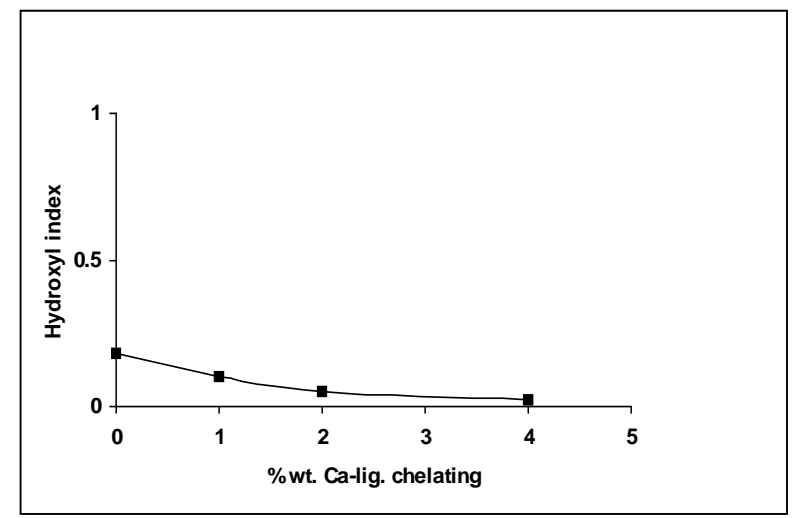

Figure 10. Relationship between the hydroxyl indix and wt \% of Ca-lignin chelating complex.

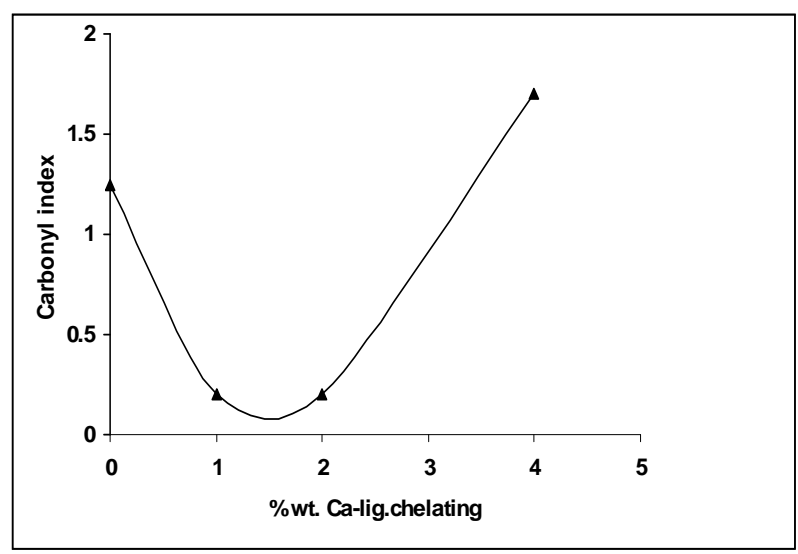

Figure 11. Relationship between the carbonyl indix and wt \% of Ca-lignin chelating complex.

creased it's contain from hydroxyl group and it's chemical reactivity to reaction with Calcium ion to form Ca-lignin chelating complex.

2) Investigating the influence of this derivative on the thermal stability of PVC showed increased thermal sta- bility of PVC by the action of it's chemical structure to absorbed $\mathrm{HCl}$ from polymer system.

3) Ca-lignin chelating complex have thermal stabilizer effect with high activity at $1 \mathrm{wt} \%$ and less activity at above percentage.

\section{Acknowledgements}

The author is grateful for the support of said Faise Jumaa Mohameed a technique in petrochemical industries for your help in FTIR measurement and said Ibraheem K. Ibraheem a researcher for his notes for complete my researcher.

\section{REFERENCES}

[1] R. F. Gould, "Lignin Structure and Reactions,” Advance in Chemistry, Series No. 59, Journal of the American Chemical Society, Washington DC, 1966.

[2] K.V. Sarkanen and C. H. Ludwing, "Lignin Occurance, Formation, Structure, and Reactions,” Wiley-Interscience \& Son Inc., New York, 1971, pp. 1-65.

[3] R. W. Heningway, A. H. Conner and S. J. Baranham, "Adhesives from Renewable Resources," Journal of the American Chemical Society, 1989, pp. 13-42.

[4] H. A. Shnawa , S. Sh. Al-Laibi and N. Sh. Addai, "Kinetic Study of Reaction the Lignin with Phenol Formaldehyde Resins,” Iraqi Journal of Polymers, Vol. 7, 2003, pp. 33-42.

[5] S. Hirose, T. Hatakeyama and H. Hatakeyama, "Synthesis and Thermal Properties of Epoxy Resins from Ester-Carboxylic Acid Derivative of Alcoholysis Lignin," Macromolecular Symposia, Vol. 179, No. 1, 2003, pp. 157-169. doi:10.1002/masy.200350715

[6] A. R. Goncalves and S. M. Luz, "Chelation of Copper (II) Ions with Kraft Lignin, 10th International Symposium on Wood and Pulping Chemistry,” Yokohama-Japan, 1999, Vol. III-Poster Presentations, pp. 410-413.

[7] A. R. Goncalves and S. M. Luz, "Evaluation of the Removal of Heavy Metals by Kraft Lignin Considering Coprecipitation," Solubility and Coordination Capacity of the Ions Tested, 6th Brazilian Symposium on the Chemistry of Lignin and Other Wood Components, Guaratingueta-SP, Brazil, 2001, pp. 266-269.

[8] G. C. Quintana, G. J. M. Rocha, A. R. Gonçalves and J. A. Velsquez, "Evaluation of Heavy Metal Removal by Oxidised Lignnins in Acid Media from Various Sources," BioResources, Vol. 3, No. 4, 2008, pp. 1092-1102.

[9] Ali T. Y. AL-Saraefi, "Efficiency Study and Comparison of Lignin as Thermal and Photo Antioxidant for Low Density Polyethylene," Master's Thesis, University of Basrah, Basrah, 2005, pp. 32-72.

[10] N. A. Mohamed and W. M. Al-Magribi, "N-(Substituted phenyl) Itaconimides as Organic Stabilizers for Rigid Poly(Vinyl Chloride) against Thermal Degradation," Polymer Degradation and Stability, Vol. 78, No. 1, 2002, pp. 149-165. doi:10.1016/S0141-3910(02)00129-5 
[11] H. F. Alfred and W. H. Raymond, "The Mechanism of Poly(Vinyl Chloride) Tabilization by Barium, Cadmium, and Zinc Carboxylates. Infrared Studies,” Journal of Polymer Science, Vol. 40, No. 137, 1959, pp. 419-431. doi:10.1002/pol.1959.1204013712

[12] J. F. Rabek, "Experimental Methods in Polymer Chemistry,” John Wiley \& Sons, New York, 1970, pp: 221-253.

[13] E. Yousif, A. Hameed, A. Kamil, Y. Farina, N. Asaad and A. Graisa, "Synthesis of New Polymers Derived from Poly (Vinyl Chloride) and Study Their Biological Evaluation," Australian Journal of Basic and Applied Sciences, Vol. 3, 2009, pp. 1786-1794.

[14] H. Mekki and M. Belbachir, "Preparation of Vinyl Chloride-Vinyl Ether Copolymers via Partial Etherification from PVC,” EXPRESS Polymer Letters, Vol. 11, 2007, pp. 495-498.

[15] A. V. Karyakin, G. V. Grishin and B. D. Kurykin, “A Study of Photodegradation of PolyvinylChloride by Infrared Spectroscopy," Polymer Science USSR, Vol. 7, No. 3, 1965, pp. 389-393. doi:10.1016/0032-3950(65)90077-8

[16] H. Kaczmarek, A. Felczak, D. Bajer and D. Bajer, "Photooxidative Degradation of Carboxylated Poly(Vinyl
Chloride)," Polymer Bulletin, Vol. 62, No. 4, 2009, pp. 503-510. doi:10.1007/s00289-008-0030-y

[17] M. Giurginca and Traian Zaharescu, "Thermo-Oxidative Degradation of Some Polymer Couples Containing HNBR,” Polymer Bulletin, Vol. 49, No. 5, 2003, pp. $357-$ 362. doi:10.1007/s00289-002-0115-y

[18] R. Rasheed, H. Mansoor, E. Yousif, A. Hameed, Y. Farina and A. Graisa, "Photostabilizing of PVC Films by 2-(Aryl)-5-[4-(Aryloxy)-Phenyl]-1,3,4-Oxadiazole Compounds," European Journal of Scientific Research, Vol 30, 2009, pp. 464-477.

[19] M. T. Taghizadeh, N. Nalbandi and A. Bahadori, "Stabilizing Effect of Epoxidized Sunflower Oil as a Secondary Stabilizer for $\mathrm{Ca} / \mathrm{Hg}$ Stabilized PVC,” EXPRESS Polymer Letters, Vol. 2, 2008, pp. 65-76.

[20] D. Braun and E. Bezdadea, "Theory of Degradation and Stabilisation Mechanisms,” In: L. I. Nass and C. A. Heiberger, Eds., Encyclopedia of PVC, Vol. 1, Mercel Deckker Inc., New York and Basel, 1986, pp. 397-429 .

[21] E. D. Owen, "Degradation and Stabilisation of PVC," Elsevier Applied Science Puplishers Ltd., London \& New York, 1984, pp: 21-252. 